\title{
Quantity of nuclear DNA in malignancies and benign lymphadenopathies associated with Epstein-Barr virus
}

\author{
T LEHTINEN, * M LEHTINEN, $\ddagger$ R AINE,* K DAMMERT, $\S$ P KULOMAA, \\ M ALAVAIKKO $\uparrow$ P LEINIKKI $\ddagger$ \\ From the ${ }^{*}$ Departments of Oncology and Pathology, Tampere University Central Hospital, $\dagger$ Department of \\ Pathology, Oulu University Central Hospital, Oulu, $\ddagger$ Department of Biomedical Sciences, University of \\ Tampere, Tampere, Finland, and \$the Kilimandzaro Christian Medical Center, Moshi, Tanzania
}

SUMMARY The quantity of nuclear DNA in 90 tumours with a strong probability of being associated with Epstein-Barr virus (EBV) (11 cases with nasopharyngeal carcinomas, seven cases of endemic and 26 of non-endemic Burkitt's lymphoma, and 46 cases of Hodgkin's disease) were analysed by flow cytometry. Twenty three cases with benign lymphadenopathies were analysed in a similar way. Except for endemic Burkitt's lymphoma most of the tumours were diploid. Near-diploid aneuploidy (with a DNA index ranging from 1.06 to 1.26) was also found in endemic Burkitt's lymphoma as well as in six non-endemic Burkitt's lymphomas and in eight cases of Hodgkin's disease but was absent in nasopharyngeal carcinomas. Tetraploid aneuploidy was seen in three cases of nasopharyngeal carcinoma. Five of the 23 cases of lymphadenopathy also showed near-diploid DNA, one of which subsequently developed into a non-Hodgkin's lymphoma. It is concluded that near-diploid DNA content seems to be associated with the lymphatic origins of the tumours rather than with EBV.

Flow cytometric analysis of DNA has shown that near-diploid aneuploidy is a characteristic feature of malignant lymphomas. ${ }^{1-4}$ In Hodgkin's disease near-diploid aneuploidy and corresponding gross secondary chromosomal aberrations have been described in flow cytometric and cytogenetic studies, respectively..$^{3-5}$ We recently reported that the flow cytometric analysis of archival non-Hodgkin's lymphoma material showed near-diploid aneuploidy in high grade non-Hodgkin's lymphomas, ${ }^{6}$ especially in non-endemic Burkitt's lymphoma. ${ }^{7}$ Secondary chromosomal abnormalities leading to a corresponding increase in DNA are also frequently seen in cytogenetic analysis of cases of endemic Burkitt's lymphoma. ${ }^{89}$

Epstein-Barr virus (EBV) infection seems to have an important role in the pathogenesis of endemic Burkitt's lymphoma. ${ }^{10}$ Because the secondary chromosomal aberrations that correspond to neardiploid DNA are particularly common in endemic Burkitt's lymphoma we decided to study their prevalence in other lymphoproliferative disorders some of which are supposed to be closely associated with EBV.

Accepted for publication 2 March 1989

\section{Material and methods}

The 33 cases of Burkitt's lymphoma were identified according to routine procedures." The 26 nonendemic cases have been described in detail elsewhere. ${ }^{7}$ Further primary diagnostic biopsy specimens obtained between 1987 and 1988 from seven cases of endemic Burkitt's lymphoma (three men, four women, age range 4 to 37 years) were from the Kilimandzaro Christian Medical Center, Tanzania.

The 45 cases of Hodgkin's disease were diagnosed between 1977 and 1987 in the catchment area of Tampere University Central Hospital, population 1000000 ( 25 men, 18 women, age range 7 to 77 years) and divided according to the Rye classification ${ }^{12}$ into lymphocyte predominance $(n=7)$, mixed cellularity $(n=12)$, nodular sclerosing $(n=20)$, and lymphocyte depleted $(n=3)$. The nodular sclerosing cases were subdivided into grade 1 (NSI, 14 cases) and grade 2 (NS2, six cases) tumours following the BNL1 criteria. ${ }^{13}$ The classification and the flow cytometric analysis were done from examination of primary tumour biopsy specimens.

The histological diagnosis of the 11 cases of nasopharyngeal carcinoma (nine men, two women, age range 16 to 82 years) was done according to the methods of Hsu et al..$^{14}$ All the tumour samples were diagnostic biopsy specimens of the primary tumour. 
Primary diagnostic biopsy specimens were available from 23 cases with benign lymphadenopathy. The cases comprised 19 patients (eight men and 11 women, age range 1 to 78 years) with various reactive lymphadenopathies, and four patients (three men and one woman, age range 17 to 67 years) with atypical lymphoid hyperplasia. The atypical hyperplasia developed later into malignant lymphoma in two cases (one case of Hodgkin's disease and one of nonHodgkin's lymphoma). One patient had an acute varicella zoster virus infection and in one case no overt or subsequent disease could be associated with the atypic hyperplasia diagnosis.

TISSUE PREPARATION AND DNA ANALYSIS

The biopsy specimens consisted of paraffin wax embedded tissue which had been prepared as described previously. ${ }^{67}$ For each analysis 10000 cells were scanned using an EPIS-C flow cytometer (Coulter Electronics, Hialeah, Florida, USA). The peak having the lowest channel number was considered to represent DNA diploid cells and to have a DNA index of $1 \cdot 0$. The DNA index of a given DNA aneuploid peak was determined as the ratio between the channel numbers of the aneuploid-diploid peak. A neardiploid aneuploid cell population was considered to exist only when two separate peaks were visible. A tetraploid aneuploid population was identified on the demonstration of corresponding S-phase cells and oktaploid peak $G_{2}$-phase $\left(G_{2}\right)$ or mitotic $(M)$ cells as described previously. ${ }^{6}$ The S-phase fraction-that is, the percentage of cells in the S-phase-was calculated by the method described by Baisch et al. ${ }^{15}$

The survival analysis and testing of significance by the log rank test were performed according to Peto et $a l .{ }^{16}$ Student's $t$ test and Fisher's exact test were used, where appropriate.

\section{Results}

The flow cytometric analysis gave good quality DNA histograms in $97 \%$ of the cases studied. Three cases of Hodgkin's disease were excluded because of unevaluable DNA histograms in repeated analyses. The mean coefficient of variation (CV, half peak) was $4.5 \%$ (range 2.8 to 7.5 ). The $\mathrm{S}$-phase fraction was estimated in all the lymphoid hyperplasias and in $92 \%$ of the malignancies.

The tumours showed near-diploid aneuploidy in four of the seven cases of endemic Burkitt's lymphoma and in six of the 26 cases of non-endemic Burkitt's lymphoma (table 1, fig 1). Two cases of non-endemic Burkitt's lymphoma were tetraploid. The DNA indices of the near-diploid aneuploid tumours varied between 1.06 and $1 \cdot 26$. Only in the cases of endemic Burkitt's lymphoma was the near-diploid aneuploidy
Table 1 No (\%) distribution of diploid $v$ aneuploid tumours in EBV associated lymphoid disorders and nasopharyngeal carcinoma

\begin{tabular}{lcllc}
\hline & Aneuploid & & \\
\cline { 2 - 5 } Category & Diploid & $\begin{array}{l}\text { Near- } \\
\text { diploid }\end{array}$ & Tetraploid & Total \\
\hline $\begin{array}{l}\text { Nasopharyngeal } \\
\text { carcinomas }\end{array}$ & $8(72)$ & & $3(28)$ & 11 \\
$\begin{array}{c}\text { Burkitt's lymphoma } \\
\text { (endemic) }\end{array}$ & $3(43)$ & $4(57)$ & & 7 \\
$\begin{array}{c}\text { Burkitt's lymphoma } \\
\text { (non-endemic) }\end{array}$ & $18(68)$ & $6(26)$ & $2(6)$ & 26 \\
Hodgkin's disease & $35(81)$ & $8(19)$ & & 43 \\
\hline
\end{tabular}
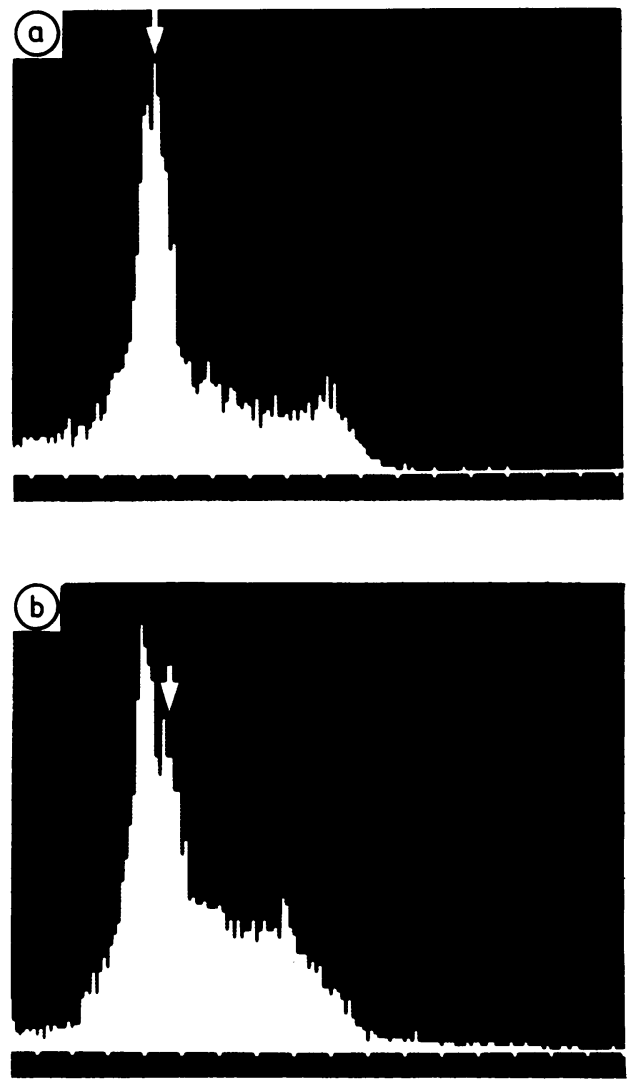

Fig 1 DNA histograms characteristic for near-diploid aneuploidy in endemic Burkitt's lymphoma (a) and non-endemic Burkitt's lymphoma (b). (a) Coefficient of variation $(C V)=7 \cdot 1 \%, S$-phase cell fraction $(S P F)=$ $28 \%, D N A$ index $(D I)=1 \cdot 11$, (b) $C V=7 \cdot 5 \%, S P F=$ $38 \%, D I=1 \cdot 13$. Arrows indicate near-diploid cell populations. 
Table 2 Characteristics of diploid $v$ aneuploid tumours in $E B V$ associated lymphoid disorders and nasopharyngeal carcinoma

\begin{tabular}{|c|c|c|c|}
\hline Category & $\begin{array}{l}5 \text { year } \\
\text { survival }\end{array}$ & $\begin{array}{l}\text { Unfavourable* } \\
v \\
\text { favourable } \\
\text { histology }\end{array}$ & $\begin{array}{l}\text { Mean } \\
\text { (SE) } \\
\text { SPF }\end{array}$ \\
\hline $\begin{array}{l}\text { Nasopharyngeal } \\
\text { carcinomas } \\
\text { Burkitt's lymphoma } \\
\text { (endemic) } \\
\text { Burkitt's lymphoma } \\
\text { (non-endemic) } \\
\text { Hodgkin's disease }\end{array}$ & \begin{tabular}{lr} 
D & ND \\
A & ND \\
D & ND \\
A & ND \\
D & \multicolumn{4}{c}{$\mathbf{4 0 \%}$} \\
A & $0 \%$ \\
D & $87 \%$ \\
A & $100 \%$
\end{tabular} & 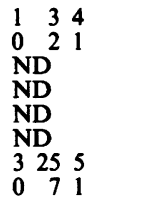 & $\begin{array}{r}6.0(1.0) \\
5.0(0) \\
16.7(4.0) \\
22.8(5.7) \\
15.9(1.3) \\
14.1(1.7) \\
1.9(0.2) \\
4.0(0.4)\end{array}$ \\
\hline
\end{tabular}

* Unfavourable $v$ favourable histology for nasopharyngeal carcinomas. keratinising squamous cell carcinoma (left), anaplastic carcinoma/ type A carcinoma (middle), and "non"-anaplastic carcinoma/type B carcinoma (right). ${ }^{4}$

* Unfavourable $v$ favourable histology for Hodgkin's disease: lymphocyte depleted (left), nodular sclerosis and mixed cellularity (middle), and lymphocytic (right). ${ }^{19}$ One diploid case could not be classified.
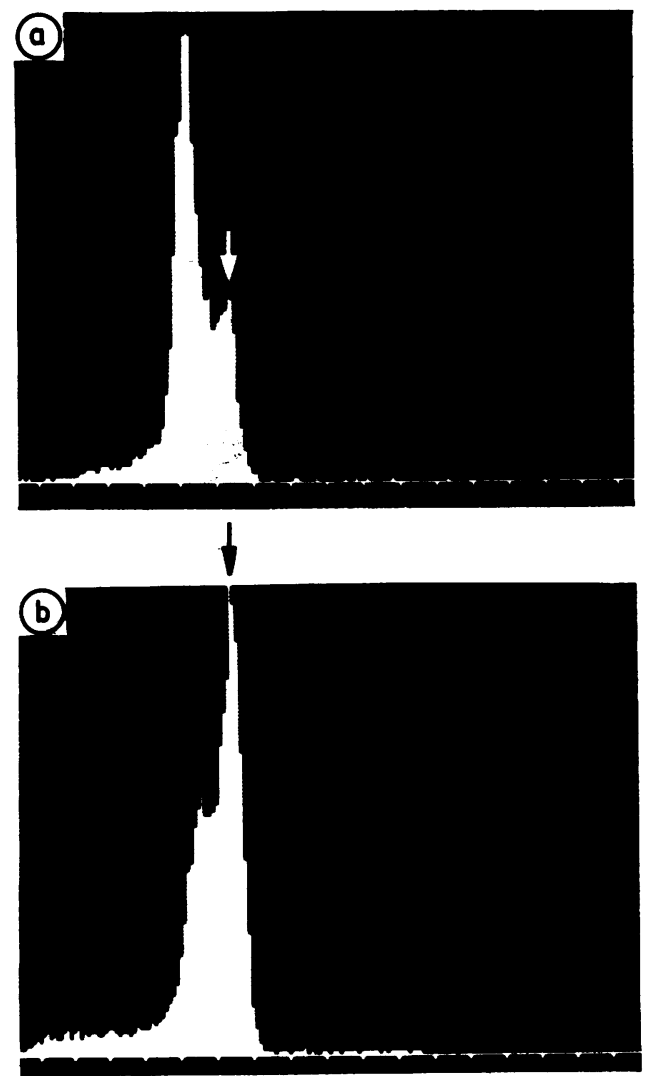

Fig 2 DNA histograms characteristic for near-diploid DNA aneuploidy in reactive lymphadenopathy $(a)$ and nodular sclerosis type Hodgkin's disease (b).

(a) $C V=6 \cdot 3 \%, S P F=2 \cdot 4 \%, D I=1 \cdot 18$,

(b) $C V=6.9 \%, S P F=4 \cdot 1 \%, D I=1 \cdot 16$
Table 3 No (\%) distribution of diploid $v$ aneuploid tumours in different benign lymphoproliferative disorders

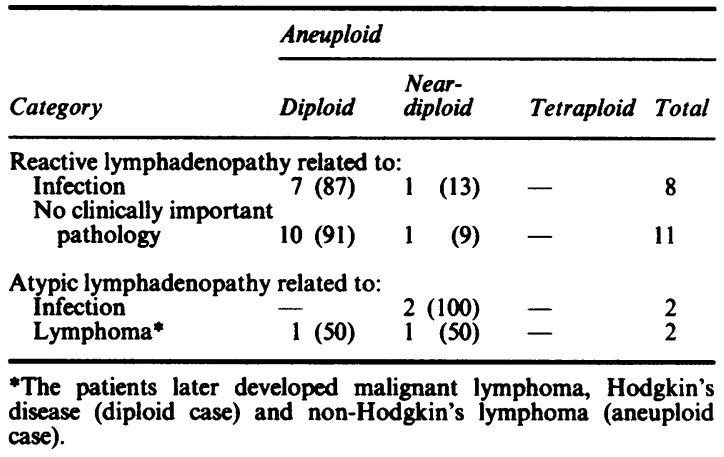

associated with an enhanced proliferative activity compared with corresponding diploid cases (table 2). In the cases of non-endemic Burkitt's lymphoma the near-diploid aneuploidy was associated with a significantly worse prognosis than diploidy $(p<0.02)$. Unfortunately, the cases of endemic Burkitt's lymphoma were too recent and few to analyse survival.

The near-diploid aneuploidy was not seen in cases of nasopharyngeal carcinoma but three cases had a tetraploid aneuploidy (table 1). The tetraploidy was not associated with unfavourable histology or prognosis in these cases (table 2).

Overall, near-diploid aneuploidy was seen in eight of $43(19 \%)$ of the cases of Hodgkin's disease (tables 1 and 2). Near-diploidy was most prevalent in the nodular sclerosing grade 1 and lymphocyte depleted type tumours (fig 2). Four of the 14 nodular sclerosing grade 1 cases and two of the seven lymphocyte depleted cases (six of $21,29 \%$ ) had near-diploid aneuploidy, while the three lymphocyte depleted type tumours were all diploid and one of the six nodular sclerosing grade 2 tumours was near-diploid (one of nine, $11 \%$ ). Significant differences in S-phase fraction were seen among the cases of Hodgkin's disease. The cases of Hodgkin's disease with near-diploid aneuploidy had a mean S-phase fraction of 4.0 (SE 0.2) compared with 1.9 (SE 0.3) seen in the diploid cases $(p=0.01$, Student's $t$ test). There were no major differences in the prognosis for near-diploid and diploid tumours (table 2) or high compared with low S-phase fraction tumours (data not shown).

Unexpectedly, near-diploid aneuploidy was found in five of 23 cases with benign lymphadenopathy (table 3). Three of the five cases presented with atypical hyperplasia and two with reactive hyperplasia. One of the atypic hyperplasia patients, a $\mathbf{3 5}$ year old man, later developed a low grade (International Working Formulation for Clinical Useage) non-Hodgkin's lymphoma (follicular, mixed small cleaved, and large cell 

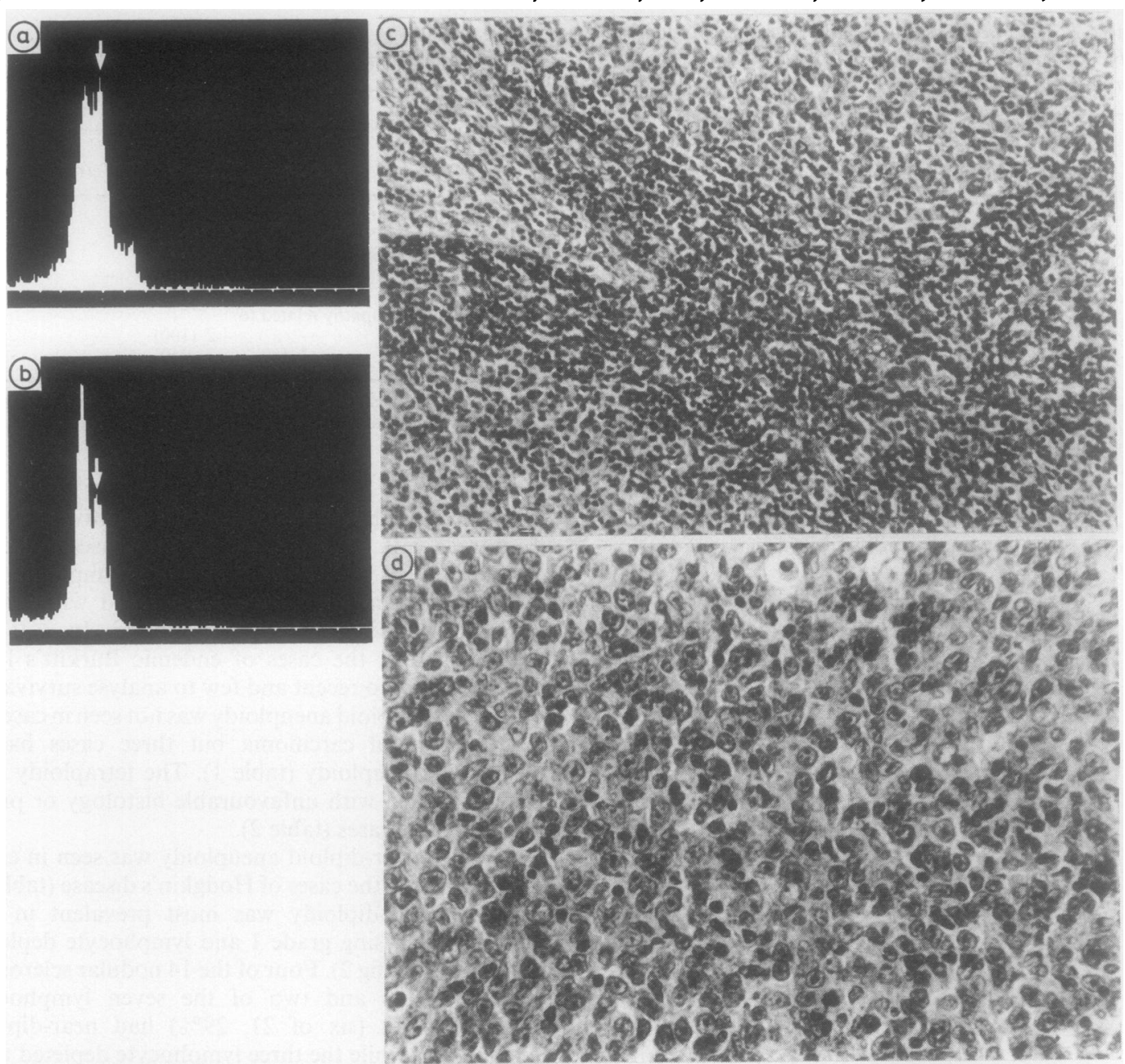

Fig 3 Consecutive DNA histograms of atypical lymphadenopathy (a) and low grade non-Hodgkin's lymphoma (b) in a 35 year old man. (a) $C V=7 \cdot 5 \%, S P F=6 \cdot 1 \%, D I=1 \cdot 16,(b) C V=7 \cdot 2 \%, S P F=7 \cdot 5 \%, D I=1 \cdot 18$.

Consecutive samples of atypical lymphadenopathy (c) and low grade non-Hodgkin's lymphoma (d) in a 35 year old man (Haematoxylin and eosin.)

lymphoma), which then transformed into high grade non-Hodgkin's lymphoma (small non-cleaved, nonBurkitt's lymphoma). Tumour samples from the two first stages of the disease atypical hyperplasia and low grade non-Hodgkin's lymphoma were available for analysis. They both showed a similar near-diploid pattern with DNA indices $1 \cdot 16$ and $1 \cdot 18$ (fig 3), respectively.

Considerable variation (range 1.2 to 8.2 ) was seen in the S-phase fraction of the samples of benign lymphadenopathy. Cases of atypical lymphoid hyperplasia showed a higher mean S-phase fraction $(5 \cdot 3, \mathrm{SE}$ $0.9)$ than cases of reactive lymphadenopathy (mean Sphase fraction 3.0, SE 0.9). The difference did, however, not reach significance.

\section{Discussion}

Flow cytometric DNA analysis of archival lymphoma and benign lymphadenopathy tissue gives results comparable with those obtained from fresh-frozen tumour samples. ${ }^{671718}$ In most cases the classification of DNA histograms into diploid, near-diploid, and tetraploid cases was possible following our first flow cytometric analysis. Two separate peaks had to be visible in repeated determinations before the sample was taken to be near-diploid.

Except for nasopharyngeal carcinomas, neardiploid aneuploidy was common in all categories studied. We found near-diploidy in most $(57 \%)$ of the cases of endemic Burkitt's lymphoma associated with 
EBV. We have previously shown near-diploid aneuploidy in a case of non-endemic Burkitt's lymphoma associated with EBV.? Cases of endemic Burkitt's lymphoma carry EBV in their tumour cells, ${ }^{19}$ but only up to $25 \%$ of non-endemic cases are positive. ${ }^{20}$ The incidence of secondary chromosomal aberrations varies from 50 to $70 \%$ and 0 to $30 \%$ in the endemic and non-endemic Burkitt's lymphomas, respectively.' The figures are similar to the distribution of neardiploid aneuploidy in our cases and may reflect an association between this pattern and EBV infection.

The flow cytometric analyses showed that none of the aneuploid nasopharyngeal carcinomas was neardiploid but that they showed tetraploidy. Tetraploidy is common in squamous cell carcinomas. ${ }^{21}$ Nasopharyngeal carcinoma has an infectious as well as a genetic aetiology. ${ }^{22}{ }^{23}$ The fact that patients with nasopharyngeal carcinoma who have skin fibroblasts are prone to have this evolve into tetraploid clones ${ }^{24}$ supports the genetic origins of aneuploidy in nasopharyngeal carcinoma. The association between EBV and nasopharyngeal carcinoma is well established. ${ }^{25}$ The EBV state was not known in our cases of nasopharyngeal carcinoma, but EBV has been found in all histological types of nasopharyngeal carcinoma. ${ }^{26}$ The lack of near-diploid aneuploidy in nasopharyngeal carcinoma refutes any role for EBV in aneuploidy.

Recent flow cytometric studies have shown neardiploid aneuploidy in Hodgkin's disease and Hodgkin's disease derived giant cells. ${ }^{34}{ }^{27}$ Cytogenetics shows gross chromosomal abnormalities in $42 \%$ of the cases of nodular sclerosing and in $24 \%$ of the remaining subtypes of Hodgkin's disease. ${ }^{5}$ In our material the proportion of aneuploid tumours was lowest $(11 \%)$ in lymphocyte depleted tumours (NS2 included) and highest $(29 \%)$ in tumours with lymphocytic predominance (NS1 included). Our results thus suggest that the origins of the proliferatively active, near-diploid cell clones in Hodgkin's disease are derived from lymphocytes. Our findings also agree with the indications that there are two different forms of nodular sclerosing type Hodgkin's disease..$^{13}$

The origins of malignant Reed-Sternberg cells in Hodgkin's disease have not been conclusively identified. ${ }^{28-30}$ Reed-Sternberg-like cells are also seen in mononucleosis. ${ }^{31}$ EBV is associated with Hodgkin's disease, ${ }^{32-34}$ and prospective seroepidemiological studies have recently strengthened the association. ${ }^{35}$ The possible role of EBV in the genesis of neardiploidy in Hodgkin's disease, however, remains open.

We found near-diploid aneuploidy in five cases with benign lymphoid hyperplasia. Aneuploidy has recently been described in other histologically benign tumours as well. ${ }^{36}{ }^{37}$ In benign, proliferatively active tissues the decondensation of cellular chromatin in- creases the DNA staining efficacy ${ }^{38}$ and might result in an arbitrarily near-diploid DNA pattern. Although this possibility can not always be excluded, the neardiploid aneuploidy has clinical importance in the diagnosis of lymphoid hyperplasia. One of our cases of hyperplasia subsequently developed a low grade nonHodgkin's lymphoma. The same near-diploid clone (with almost identical DNA indices) was present in the consecutive biopsy specimens where the diagnoses of atypical hyperplasia and the low grade non-Hodgkin's lymphoma were made. Thus the change in the ploidy may occur early during lymphomagenesis.

Translocation $\mathrm{t}(14 ; 18)$ has been identified as one of the primary events in lymphomagenesis and was the only specific chromosomal change related to the development of near-diploidy in already existing lymphomas. ${ }^{39}$ Gain of chromosomal material reflected as chromosomal near-diploidy follows the loss of chromosome $17 \mathrm{p}$ or chromosome 18 in colorectal tumours..$^{40}$ Whether the translocation $t(14 ; 18),{ }^{3941}$ or $t(2 ; 19)$ found in an atypical lymphoid hyperplasia case, ${ }^{42}$ result in the extra chromosomal material acquired at the early stage of lymphomagenesis warrants further investigation.

The excellent technical assistance of Mrs Leena Pankko is gratefully acknowledged. This study was supported by Finnish Cancer Organizations research grant and by the Pirkanmaa Cancer Fund.

\section{References}

1 Tribukait B. Clinical DNA flow cytometry. Med Oncol Tumor Pharmacother 1984;1:211-8.

2 Christensson B, Tribukait B, Linder I-L, Ullman B, Biberfeld P. Cell proliferation and DNA content in non-Hodgkin's lymphoma. Flow cytometry in relation to lymphoma classification. Cancer 1986;58:1295-304.

3 Morgan KG, Quirke P, O'Brien CJ, Bird CC. Hodgkin's disease; a flow cytometric study. J Clin Pathol 1988;41:365-9.

4 Joensuu H, Klemi PJ, Korkeila E. Prognostic value of DNA ploidy and proliferative activity in Hodgkin's disease. Am J Clin Pathol (in press).

5 Kristoffersson U, Heim S, Mandahl N, Olsson H, Åkerman M, Mitelman F. Cytogenetic studies in Hodgkin's disease. Acta Pathol Microbiol Immunol Scand 1987;95:289-95.

6 Lehtinen T, Aine R, Lehtinen M, et al. Flow cytometric DNAanalysis of 199 favourable and unfavourable histology nonHodgkin's lymphomas. J Pathol 1989;157:27-36.

7 Lehtinen T, Lehtinen M, Aine R, et al. Nuclear DNA-content of non-endemic Burkitt's lymphomas. J Clin Pathol 1987;40: 1201-5.

8 Berger R, Bernheim A. Cytogenetic studies on Burkitt's lymphoma-leukemia. Cancer Genet Cytogenet 1982;7:231-44.

9 Zech L, Maglund U, Nilsson K, Klein G. Characteristic chromosomal abnormalities in biopsies and lymphoid cell lines from patients with Burkitt and non-Burkitt's lymphomas. Int $J$ Cancer 1976;17:47-56.

10 Klein G, Klein E. Evolution of tumours and the impact of molecular oncology. Nature 1985;315:190-5. 
11 Aine R. Small non-cleaved follicular center cell lymphoma: clinicopathologic comparison of Burkitt and non-Burkitt variants in Finnish material. Eur J Cancer Clin Oncol 1985; 21:1179-85.

12 Lukes RJ, Craven LF, Hall TC, Rappaport H, Ruben P. Report of the nomenclature committee. Cancer 1966;19:317-44.

13 Bennett MH, Tu A, Hudson GV. Analysis of grade 1 Hodgkin's disease (Report No 6). Clin Radiol 1981;32:491-8.

14 Hsu H-C, Chen C-L, Hsu M-M, Lynn T-C, Tu S-M, Huang S-C. Pathology of Nasopharyngeal carcinoma. Proposal of a new histologic classification correlated with prognosis. Cancer 1987;59:945-51.

15 Baisch H, Gohde W, Linden WA. Analysis of PCP-data to determine the fraction of cells in the various phases of the cell cycle. Radiat Environ Biophys 1975;12:31-9.

16 Peto R, Pike MC, Armitage P, et al. Design and analysis of randomized clinical trials requiring prolonged observation of each patient II. Analysis and examples. Br J Cancer 1977;35: 1-39.

17 Camplejohn RS, MacCartney JC. Comparison of DNA flow cytometry from fresh and paraffin embedded samples of nonHodgkin's lymphoma. J Clin Pathol 1985;38:1096-9.

18 Joensuu H, Klemi PJ, Eerola E. Diagnostic value of DNA flow cytometry combined with fine needle aspiration biopsy in lymphomas. J Pathol 1988;154:237-45.

19 Lindahl T, Klein G, Reedman B, Johansson B, Singh S. Relationship between Epstein-Barr virus (EBV) DNA and the EBVdetermined nuclear antigen (EBNA) in Burkitt lymphoma biopsies and other lymphoproliferative malignancies. Int $J$ Cancer 1974;13:764-72.

20 Ziegler JL, Andersson M, Klein G, Henle W. Detection of EpsteinBarr virus in American Burkitt's lymphoma. Int J Cancer 1976; 17:701-6.

21 Johnson TS, Adelson MD, Sneige N, et al. Cervical carcinoma DNA-content S-fraction and malignancy grading. I. Interrelationships. Gynecol Oncol 1987;26:41-56.

22 Young LS, Sixbey JW, Clark C, Rickinson AB. Epstein-Barr virus receptors on human pharyngeal epithelia. Lancet 1986;:240-2.

23 Ho JHC. Epidemiology of nasopharyngeal carcinoma. J R Coll Surg (Edin) 1975;20:223-35.

24 Danes BS, Boyle PD, Tragnos F, Ringborg U, Melamed MR. Evidence for genetic predisposition for some nasopharyngeal cancers by in vitro hyperdiploidy in human dermal fibroblasts. Cancer Genet Cytogenet 1987;26:261-70.

25 Zeng Y, Zhang LG, Wu YC, et al. Prospective studies on nasopharyngeal carcinoma in Epstein-Barr virus IgA/VCA antibody-positive persons in Wuzhou City, China. Int J Cancer 1985;36:545-7.

26 Raab-Traub N, Flynn K, Pearson G, et al. The differentiated form of nasopharyngeal carcinoma contains Epstein-Barr virus DNA. Int J Cancer 1987;39:25-9.

27 Olsson L, Behnke O, Pleibel N, et al. Establishment and characterization of a cloned giant cell line from a patient with Hodgkin's disease. JNCI 1984;4:809-17.
28 Diehl V, Pfreundschuh M, Fonatsch C, et al. Phenotypic and genotypic analysis of Hodgkin's disease derived cell lines: histopathological and clinical implications. Cancer Surveys $1985 ; 4: 399-419$.

29 Angel CA, Warford A, Campbell AC, Pringle JH, Lauder I. The immunohistology of Hodgkin's disease-Reed-Sternberg cells and their variants. J Pathol 1987;153:21-30.

30 Bucsky P. Hodgkin's disease: The Sternberg-Reed cell. Blut 1987; 55:413-20.

31 Hsu S-M, Zhao X. The H-R-S-like cells in infectious mononucleosis are transformed interdigitating reticulum cells. $\mathrm{Am} \mathrm{J}$ Pathol 1987;127:403-8.

32 Newell GR, Lynch HK, Gibeau JM, Spitz MR. Seasonal diagnosis of Hodgkin's disease among young adults. JNCI 1985;71:53-5.

33 Poppema S, van Imhoff G, Torensma R, Smit J. Lymphadenopathy morphologically consistent with Hodgkin's disease associated with Epstein-Barr virus infection. Am J Clin Pathol 1985;84:385-90.

34 Evans AS, Gutensohn NM. A population-based case-control study of EBV and other viral antibodies among persons with Hodgkin's disease and their siblings. Int J Cancer 1984;34: 149-57.

35 Evans AS, Mueller NM. Prospective seroepidemiological studies of Epstein-Barr virus in Hodgkin's disease in sera obtained prior to diagnosis. In: Klaukka T, Piha T, Poikolainen K, Sahi T, eds. Abstracts of the Xth Congress of the International Epidemiology Association. IEA: Helsinki, 1987.

36 Ingh van den HF, Griffoen G, Cornelisse CJ. Flow cytometric detection of aneuploidy in colorectal adenomas. Cancer Res 1985;45:3392-7.

37 Joensuu H, Klemi P, Eerola E. DNA aneuploidy in follicular adenomas of the thyroid gland. Am J Pathol 1986;124:373-6.

38 Darzynkiewitz Z, Traganos F, Kapuscinski J, Staiano-Coico L, Melamed MR. Accessibility of DNA in situ to various fluorochromes: relationship to chromatin changes during erythropid differentiation of Friend leukemia cells. Cytometry 1984;5: 355-63.

39 Sanger WG, Armitage J, Bridge J, Weisenburger D, Fordyce R, Purtilo DT. Initial and subsequent cytogenetic studies in malignant lymphoma. Cancer 1987;69:3014-19.

40 Muleris M, Salmon RJ, Dutrillaux B. Existence of two distinct processes of chromosomal evolution in near-diploid colorectal tumors. Cancer Genet Cytogenet 1988;32:43-50.

41 Yunis J, Frizzera G, Oken M, McKenna J, Theologides A, Arnesen M. Multiple recurrent genomic defects in follicular lymphoma. A possible model cancer. N Engl J Med 1987;316: 79-84.

42 Chenevix-Trench G, Cowan JM, Behm FG, et al. Cytogenetic and molecular genetic studies of a patient with atypical lymphoid hyperplasia. Cancer Genet Cytogenet 1987;27:251-9.

Requests for reprints to: Dr Tuula Lehtinen, Department of Biomedical Sciences, University of Tampere, POB 607, Tampere, SF-33101, Finland. 